\title{
Practice guideline update summary: Botulinum neurotoxin for the treatment of blepharospasm, cervical dystonia, adult spasticity, and headache
}

Report of the Guideline Development Subcommittee of the American Academy of Neurology

David M. Simpson, MD

Mark Hallett, MD

Eric J. Ashman, MD

Cynthia L. Comella, MD

Mark W. Green, MD

Gary S. Gronseth, MD

Melissa J. Armstrong,

MD

David Gloss, MD

Sonja Potrebic, MD, PhD

Joseph Jankovic, MD

Barbara P. Karp, MD

Markus Naumann, MD

Yuen T. So, MD, PhD

Stuart A. Yablon, MD

Correspondence to

American Academy of Neurology:

guidelines@aan.com

\section{Supplemental data} at Neurology.org

\section{ABSTRACT}

Objective: To update the 2008 American Academy of Neurology (AAN) guidelines regarding botulinum neurotoxin for blepharospasm, cervical dystonia (CD), headache, and adult spasticity.

Methods: We searched the literature for relevant articles and classified them using 2004 AAN criteria.

Results and recommendations: Blepharospasm: OnabotulinumtoxinA (onaBoNT-A) and incobotulinumtoxinA (incoBoNT-A) are probably effective and should be considered (Level B). AbobotulinumtoxinA (aboBoNT-A) is possibly effective and may be considered (Level C). CD: AboBoNT-A and rimabotulinumtoxinB (rimaBoNT-B) are established as effective and should be offered (Level A), and onaBoNT-A and incoBoNT-A are probably effective and should be considered (Level B). Adult spasticity: AboBoNT-A, incoBoNT-A, and onaBoNT-A are established as effective and should be offered (Level A), and rimaBoNT-B is probably effective and should be considered (Level B), for upper limb spasticity. AboBoNT-A and onaBoNT-A are established as effective and should be offered (Level A) for lower-limb spasticity. Headache: OnaBoNT-A is established as effective and should be offered to increase headache-free days (Level A) and is probably effective and should be considered to improve health-related quality of life (Level B) in chronic migraine. OnaBoNT-A is established as ineffective and should not be offered for episodic migraine (Level A) and is probably ineffective for chronic tension-type headaches (Level B). Neurology ${ }^{\circledR}$ 2016;86:1818-1826

\section{GLOSSARY}

AAN = American Academy of Neurology; aboBoNT-A = abobotulinumtoxinA; $\mathbf{A E}=$ adverse event; $\mathbf{B D I}=$ Blepharospasm Disability Index; BoNT = botulinum neurotoxin; $\mathbf{C D}=$ cervical dystonia; $\mathbf{C l}=$ confidence interval; $\mathbf{C M}=$ chronic migraine; DAS = Disability Assessment Scale; EM = episodic migraine; incoBoNT-A = incobotulinumtoxinA; onaBoNT-A = onabotulinumtoxinA; $\mathbf{Q O L}=$ quality of life; $\mathbf{R D}=$ risk difference; rimaBoNT-B = rimabotulinumtoxinB; $\mathbf{R M T}$ = randomized, masked trials; TWSTRS = Toronto Western Spasmodic Torticollis Rating Scale; TZD = tizanidine.

This article summarizes information provided in the complete guideline, available on the Neurology ${ }^{\circledR}$ Web site at Neurology.org. Tables e-1 through e-6 and appendices e-1 through e-5, cited in the full guideline (data supplement), as well as references e1 through e16, cited in this summary, are available at Neurology.org.

In 2008, the American Academy of Neurology (AAN) published guidelines on the uses of botulinum neurotoxin (BoNT). ${ }^{1-3}$ New research on 4 indications-blepharospasm, cervical dystonia (CD), spasticity, and headache-prompted this update.
BoNT pharmacology is reviewed in the 2008 AAN guidelines. ${ }^{1-3}$ BoNT is commercially available in 2 serotypes, A and B. There are 4 US Food and Drug Administration-approved preparations of BoNT: onabotulinumtoxinA (onaBoNT-A), abobotulinumtoxinA (aboBoNT-A), incobotulinumtoxinA (incoBoNT-A), and rimabotulinumtoxinB (rimaBoNT-B) (table 1). The regulatoryapproved indications do not necessarily correspond to those in the evidence-based recommendations presented here.

From the Department of Neurology (D.M.S., M.W.G.), Icahn School of Medicine at Mount Sinai, New York, NY; Human Motor Control Section (M.H.), National Institute of Neurological Disorders and Stroke (B.P.K.), National Institutes of Health, Bethesda, MD; Department of Neurology (E.J.A.), Bronson Neuroscience Center, Bronson Methodist Hospital, Kalamazoo, MI; Department of Neurological Sciences (C.L.C.), Rush University Medical Center, Chicago, IL; Department of Neurology (G.S.G.), University of Kansas School of Medicine, Kansas City; Department of Neurology (M.J.A.), University of Maryland, Baltimore; Department of Neurology (D.G.), Geisinger Health System, Danville, PA; Department of Neurology (S.P.), Kaiser Permanente Los Angeles Medical Center, CA; Parkinson's Disease Center and Movement Disorders Clinic (J.J.), Department of Neurology, Baylor College of Medicine, Houston, TX; Department of Neurology and Clinical Neurophysiology (M.N.), Klinikum Augsburg, Germany; Department of Neurology and Neurological Sciences (Y.T.S.), Stanford University, Palo Alto, CA; and Division of Physical Medicine and Rehabilitation (S.A.Y.), University of Alberta, Edmonton, Canada.

Approved by the Guideline Development Subcommittee on November 16, 2013; by the Practice Committee on February 27, 2015; and by the AAN Institute Board of Directors on January 19, 2016.

Go to Neurology.org for full disclosures. Funding information and disclosures deemed relevant by the authors, if any, are provided at the end of the article. 


\begin{tabular}{|lll|}
\hline $\begin{array}{l}\text { Table } 1 \\
\text { BoNT preparation }\end{array}$ & Brand name (manufacturer) & FDA-approved indications \\
OnabotulinumtoxinA & Botox (Allergan, Inc., Irvine, CA) & $\begin{array}{l}\text { Blepharospasm, CD, upper } \\
\text { extremity spasticity, lower } \\
\text { extremity spasticity, CM }\end{array}$ \\
AbobotulinumtoxinA & Dysport (Ipsen Ltd., Paris, France) & $\begin{array}{l}\text { CD, upper extremity } \\
\text { spasticity }\end{array}$ \\
IncobotulinumtoxinA & $\begin{array}{l}\text { Xeomin (Merz Pharmaceuticals, } \\
\text { Frankfurt, Germany) }\end{array}$ & $\begin{array}{l}\text { Blepharospasm, CD, upper } \\
\text { extremity spasticity }\end{array}$ \\
RimabotulinumtoxinB & $\begin{array}{l}\text { Myobloc Neurobloc (US } \\
\text { WorldMeds/Solstice Neurosciences, } \\
\text { Louisville, KY) }\end{array}$ & CD \\
\hline
\end{tabular}

Abbreviations: BoNT = botulinum neurotoxin; $\mathrm{CD}=$ cervical dystonia; $\mathrm{CM}=$ chronic migraine; FDA = Food and Drug Administration.

${ }^{a}$ FDA approvals relevant to this review. superior to placebo (difference in change in Jankovic Rating Score ${ }^{6}$ at week 6, 1.0, 95\% confidence interval [CI] 0.5-1.4). Benefit lasted a median of 10.6 weeks.

A Class II placebo-controlled RMT ${ }^{7}$ observed that aboBoNT-A ( $40 \mathrm{U}, 80 \mathrm{U}$, or $120 \mathrm{U}$ ) improved disability in a dose-related manner on active treatment as measured by the Blepharospasm Disability Index ${ }^{8}$ (BDI) (median change in BDI after $80 \mathrm{U}-3.0$, $95 \%$ CI -4.0 to -1.0 ). Benefit lasted 12 weeks with $40 \mathrm{U}$ and up to 16 weeks with $80 \mathrm{U}$ or $120 \mathrm{U}$.

A second Class I RMT comparing onaBoNT-A with incoBoNT-A (1:1 dosing $)^{9}$ found comparable magnitude (change in BDI $-2.0, p=0.148$ ) and duration of benefit (13 weeks) between BoNT preparations.

A second Class II RMT compared onaBoNT-A and incoBoNT-A at the same dose with injections to one eye with one drug and the other eye with the other drug (injected side randomly assigned). No differences were found with multiple measures over 5 treatment sessions. ${ }^{10}$

Commonly reported adverse events (AEs) with BoNT injections included periorbital hematoma (25\%), ptosis (range of risk differences [RDs] 13\%$54 \%$ ), dry eyes (range of RDs $7.1 \%-13 \%$ ), and blurred vision (RD 42\%).

Four Class IV observational studies reported longterm outcomes. Benefit from aboBoNT-A or onaBoNT-A was sustained for at least 15 years in 128 patients, ${ }^{11}$ onaBoNT-A for 10 years in 83 patients, ${ }^{12}$ and incoBoNT-A for 69 weeks in $82 \mathrm{pa}$ tients. ${ }^{13}$ In 288 patients arbitrarily assigned to toxin formulation, similar degrees of benefit were sustained for at least 10 years (onaBoNT-A), 15 years (aboBoNT-A), and 5 years (incoBoNT-A). ${ }^{14}$

No studies meeting inclusion criteria were found for rimabotulinumtoxin for treatment of blepharospasm.

Conclusions. OnaBoNT-A (2 Class II studies from 2008 guideline) and incoBoNT-A (1 Class I study) are probably safe and effective, and aboBoNT-A (1 Class II study) is possibly effective, for treating blepharospasm. There is insufficient evidence to determine the efficacy of rimaBoNT-B.

IncoBoNT-A and onaBoNT-A (1 Class I comparative effectiveness study from the 2008 guideline and 2 more recent comparative effectiveness studies [Class I and 1 Class II]) are equivalent in efficacy for treating blepharospasm. AboBoNT-A and onaBoNT-A (1 Class II study from the 2008 guideline) are possibly equivalent for treating blepharospasm.

Recommendations. OnaBoNT-A and incoBoNT-A injections should be considered (Level B), and aboBoNT-A may be considered (Level C), as treatment options for blepharospasm.

Clinical context. BoNT is considered the first-line treatment of blepharospasm by most movement 


\begin{tabular}{|c|c|c|c|c|c|c|}
\hline \multirow{2}{*}{$\begin{array}{l}\text { Table } 2 \\
\text { Indication }\end{array}$} & \multicolumn{6}{|c|}{ Evidence-based conclusions and recommendations for the efficacy of various botulinum neurotoxin formulations by indication } \\
\hline & Level $A^{a}$ effective & $\begin{array}{l}\text { Level } B^{\mathrm{b}} \text { probably } \\
\text { effective }\end{array}$ & $\begin{array}{l}\text { Level } C^{c} \text { possibly } \\
\text { effective }\end{array}$ & $\begin{array}{l}\text { Level } U^{d} \text { insufficient } \\
\text { evidence }\end{array}$ & $\begin{array}{l}\text { Level } A^{e} \\
\text { ineffective }\end{array}$ & $\begin{array}{l}\text { Level } B^{f} \\
\text { ineffective }\end{array}$ \\
\hline Blepharospasm & & $\begin{array}{l}\text { OnabotulinumtoxinA, } \\
\text { incobotulinumtoxinA }\end{array}$ & AbobotulinumtoxinA & RimabotulinumtoxinB & & \\
\hline Cervical dystonia & $\begin{array}{l}\text { AbobotulinumtoxinA, } \\
\text { rimabotulinumtoxinB }\end{array}$ & $\begin{array}{l}\text { OnabotulinumtoxinA, } \\
\text { incobotulinumtoxinA }\end{array}$ & & & & \\
\hline $\begin{array}{l}\text { Upper limb } \\
\text { spasticity }\end{array}$ & $\begin{array}{l}\text { Abobotulinumtoxin } \mathrm{A}_{,} \\
\text {onabotulinumtoxin } \mathrm{h}^{,} \\
\text {incobotulinumtoxin } \mathrm{A}\end{array}$ & RimabotulinumtoxinB & & & & \\
\hline $\begin{array}{l}\text { Lower limb } \\
\text { spasticity }\end{array}$ & $\begin{array}{l}\text { OnabotulinumtoxinA, } \\
\text { abobotulinumtoxin } \mathrm{A}\end{array}$ & & & $\begin{array}{l}\text { IncobotulinumtoxinA, } \\
\text { rimabotulinumtoxinB }\end{array}$ & & \\
\hline Chronic migraine & Onabotulinumtoxin $A^{i}$ & & & & & \\
\hline Episodic migraine & & & & & Onabotulinur & \\
\hline $\begin{array}{l}\text { Tension-type } \\
\text { headache }\end{array}$ & & & & & & OnabotulinumtoxinA \\
\hline $\begin{array}{l}\text { Abbreviations: abo } \\
\text { rimabotulinumtoxin } \\
\text { a Level A recommen } \\
{ }^{\mathrm{b}} \text { Level B recommen } \\
{ }^{\mathrm{c}} \text { Level C recommen } \\
{ }^{\mathrm{d}} \text { Level U recommen } \\
{ }^{\mathrm{e}} \text { Level A recommen } \\
{ }^{\mathrm{f}} \text { Level B recommen } \\
{ }^{\mathrm{g}} \text { Evidence demonst } \\
{ }^{\mathrm{h}} \text { Probably superior } \\
{ }^{\mathrm{i}} \text { Established as effe }\end{array}$ & $\begin{array}{l}\text { NT-A abobotul } \\
\text { tion for effectivenes } \\
\text { tion for effectivenes } \\
\text { tion for effectivenes } \\
\text { tion signifies insuffic } \\
\text { tion for ineffectiven } \\
\text { tion for ineffectivene } \\
\text { tes efficacy in reduci } \\
\text { tizanidine and exerc }\end{array}$ & $\begin{array}{l}\text { numtoxinA; incoBoN } \\
\text { s signifies interventio } \\
\text { s signifies interventio } \\
\text { s signifies interventio } \\
\text { ient evidence to supp } \\
\text { ss signifies intervent } \\
\text { ss signifies intervent } \\
\text { ng spasticity but is in } \\
\text { se alone for reducing }\end{array}$ & $\begin{array}{l}\text { T-A }=\text { incobotulin } \\
\text { should be offered. } \\
\text { should be consider } \\
\text { may be considered. } \\
\text { ort or refute effectiv } \\
\text { on should not be off } \\
\text { on should not be con } \\
\text { adequate to determir } \\
\text { spasticity. }\end{array}$ & $\begin{array}{l}\text { ImtoxinA; onaBoNT-A } \\
\text { d. } \\
\text { eness of intervention. } \\
\text { red. } \\
\text { sidered. } \\
\text { le improvement in activ }\end{array}$ & $=$ onabc & $\begin{array}{l}\text { inA; rimaBoNT-B = } \\
\text { with limb spasticity. }\end{array}$ \\
\hline
\end{tabular}

disorder specialists. ${ }^{15}$ All 3 type A toxins appear to have similar efficacy and can continue to be efficacious over long periods.

Cervical dystonia. CD is characterized by involuntary contractions of neck and upper shoulder muscles, resulting in abnormal postures or movements (or both) of the neck, shoulder, and head. ${ }^{16}$

The 2008 guideline ${ }^{2}$ concluded that BoNT is established as safe and effective for CD treatment on the basis of 1 Class I trial of onaBoNT-A, 2 Class I trials of aboBoNT-A, and 3 Class I trials of rimaBoNT-B. Moreover, on the basis of a single Class I study comparing aboBoNT-A with trihexyphenidyl, the guideline concluded that BoNT is probably more efficacious and better tolerated than trihexyphenidyl.

Since the 2008 guideline publication, 1 placebocontrolled Class I study ${ }^{17}$ found that incoBoNT-A (120 U, 240 U) improved Toronto Western Spasmodic Torticollis Rating Scale (TWSTRS) ${ }^{18}$ total scores from baseline to week 4 (placebo $=-2.2$, $120 \mathrm{U}=-9.9$, and $240 \mathrm{U}=-10.9, p<0.001$ ). A second study (Class II) comparing 2 doses of incoBoNT-A (120 U or $240 \mathrm{U})^{19}$ demonstrated that both doses provided significant improvements in mean TWSTRS total scores, and in severity, disability, and pain subscores, from each injection session to the respective 4-week follow-up visit. There was no significant difference in efficacy between the 2 studied doses, although the study was not powered to demonstrate such differences. The most frequently reported $\mathrm{AE}$ in the incoBoNT-A groups in this study was dysphagia $(23.4 \%$ in the $240 \mathrm{U}$ dose group and $10.7 \%$ in the $120 \mathrm{U}$ dose group).

Another placebo-controlled study (Class II) of onaBoNT-A (the original Botox formulation containing $25 \mathrm{mg}$ of neurotoxin complex protein per 100 $\mathrm{U})^{20}$ found that onaBoNT-A produced greater improvements in the CD Severity Scale $(-1.81$ vs -0.31 points, $p=0.012)$ and Global Assessment Scale $(61.7 \%$ vs $41.6 \%$ improved, $p=0.022)$. Rhinitis and treatment-related dysphagia were more frequent with onaBoNT-A.

Five studies compared different formulations of BoNT. The first 2 studies (Class I) ${ }^{21,22}$ randomized patients with CD to onaBoNT-A (150-250 U) or rimaBoNT-B (10,000 U) and noted similar durations of effect and no significant difference in improved TWSTRS scores at 4 weeks. Dysphagia occurred more frequently in the rimaBoNT-B group in both studies ( $48 \%$ vs $19 \%$ in the first study and $16 \%$ vs $14.5 \%$ in the second study).

The third Class I study ${ }^{23}$ compared the effect of onaBoNT-A 70-240 U with aboBoNT-A 240-720 $\mathrm{U}$ and observed no difference in the improvement of posttreatment Tsui scores at 4 weeks (mean difference $0.2,95 \%$ CI -0.7 to 1.1 , lower scores with aboBoNT-A). In a Class II 9-month randomized, double-blind, multicenter, noninferiority, 2-period crossover study with a 2.5:1 (aboBoNT-A:onaBoNT-A) protocol involving 103 patients with CD, 
94 of whom completed the study, there were no statistically significant differences between aboBoNT-A and onaBoNT-A in mean changes in the Tsui scale (0.8 points favoring onaBoNT-A, $95 \% \mathrm{CI}-0.1$ to 1.7), TWSTRS, global impression, or frequency of AEs from baseline to 4 weeks after each injection. ${ }^{24}$ In another comparison study (Class II), 46 patients with $\mathrm{CD}$ were enrolled in a double-blind, randomized, crossover trial of onaBoNT-A vs aboBoNT-A in 1:3 dose conversion ratios. There was no significant difference between the 2 products at week 4 , but at week 12 there was a significantly shorter duration and lower efficacy of onaBoNT-A assessed by reduction in TWSTRS total score, suggesting that the optimal conversion ratio between onaBoNT-A and aboBoNT-A is lower than $1: 3 .^{25}$

Three long-term, prospective, open-label studies (Class IV $)^{26-28}$ evaluated the clinical response of repeated injections of onaBoNT-A and found persistent benefit for up to 2 years.

Conclusions. AboBoNT-A (2 Class I studies reviewed in the 2008 guideline) and rimaBoNT-B (3 Class I studies reviewed in the 2008 guideline) are established as safe and effective for the treatment of CD.

OnaBoNT-A (1 Class I study reviewed in the 2008 guideline, 1 more recent Class II study) and incoBoNT-A (1 more recent Class I study) are probably safe and effective for the treatment of CD.

RimaBoNT-B and onaBoNT-A (2 Class I comparative effectiveness studies) are equivalent in efficacy for treating CD. AboBoNT-A and onaBoNT-A (1 Class I study) are probably equivalent for treating $\mathrm{CD}$.

Recommendations. AboBoNT-A and rimaBoNT-B should be offered (Level A), and onaBoNT-A and incoBoNT-A should be considered (Level B), as options for the treatment of CD.

Clinical context. BoNT is accepted as first-line treatment for CD. Although the evidence levels may differ across BoNT serotypes and brands, all formulations have regulatory approval and are commonly used. There is an extensive clinical history of onaBoNT-A and incoBoNT-A use, but the lack of additional Class I studies led to only a Level B recommendation. Comparative trials indicate similar efficacy for rimaBoNT-B and onaBoNT-A, and for aboBoNT-A and onaBoNT-A, in the treatment of CD.

Spasticity in adults. A 2010 AAN guideline provides recommendations for BoNT treatment of spasticity in pediatric patient populations, ${ }^{29}$ and therefore this review discusses only adult spasticity.

The 2008 guideline $^{1}$ concludes that BoNT is established as effective in the treatment of adult spasticity in the upper extremity on the basis of 6 Class I studies of aboBoNT-A, 4 Class I studies of onaBoNT-A, and 1 Class I study of rimaBoNT-B.
The guideline also concludes that BoNT is effective in treating lower limb spasticity on the basis of 2 Class I studies of aboBoNT-A and 1 Class I study of onaBoNT-A. Studies demonstrated that BoNT is effective for reducing muscle tone and improving passive function (e.g., improved range of motion) and is probably effective for improving active function (1 Class I study of aboBoNT-A).

Upper extremity spasticity. AboBoNT-A. Four new Class I trials ${ }^{30-33}$ investigating aboBoNT-A demonstrated significant reductions in upper limb tone as measured by the modified Ashworth scale. These studies also measured functional outcomes. The first study ${ }^{30}$ demonstrated no significant difference in quality of life (QOL) but observed significantly greater global benefit in patients given BoNT. The second study ${ }^{31}$ observed no significant difference between groups for improved active arm function as measured by the Action Research Arm Test at 1 month (RD favoring the BoNT group 5.7\%, 95\% CI $-3.5 \%$ to $14.6 \%$ ). However, participants treated with aboBoNT-A showed improvement in upper limb muscle function at 3 months as measured by the Motricity Index (mean change in index 3.5, 95\% CI 0.1 to 6.8, greater number of points in the intervention group). The third study ${ }^{32}$ demonstrated no significant change in functional assessment scores. The fourth, a more recent study, ${ }^{33}$ showed improved response rate $(>1$ point) on the principal target of treatment of the Disability Assessment Scale (DAS), a measure of selfreported disability, at 4 weeks among participants treated with 1,000 U of aboBoNT-A, but not with $500 \mathrm{U}$ or placebo $(62 \%$ in $1,000 \mathrm{U}, p=0.0018$ vs placebo; $50 \%$ in $500 \mathrm{U}, p=0.1279$ vs placebo; and $39.2 \%$ in placebo). The higher-dose BoNT-A group also demonstrated improved active range of motion in the elbow, wrist, and fingers.

A fifth Class I study ${ }^{34}$ of patients with upper limb spasticity focused on caregiver burden. This study found that $67 \%$ of caregivers of patients receiving aboBoNT-A reported a $\geq 4$-point reduction on the carer burden scale as compared with $20 \%$ of caregivers of patients injected with saline $(p=0.001)$.

OnaBoNT-A. Four studies (3 Class I, ${ }^{35-37} 1$ Class $\mathrm{II}^{38}$ ) demonstrated consistent efficacy in tone reduction in the upper limb from onaBoNT-A. Scores on the DAS improved only in patients choosing improved limb position ${ }^{35,38}$ and dressing ${ }^{36}$ as principal treatment goals. One of the Class I studies ${ }^{37}$ enrolled 21 patients and failed to demonstrate significant effects of BoNT on many functional outcomes. However, this study was underpowered to exclude potentially important differences. In these studies onaBoNT-A was well tolerated, with no significant difference observed in the overall $\mathrm{AE}$ incidence between treatment and placebo groups. 
Using goal attainment scaling scores as the primary endpoint measure, another Class I study (prospective, double-blind) randomized participants to 1 of 2 groups: onaBoNT-A plus standard of care or placebo plus standard of care. No difference was found between groups with respect to achievement of principal and secondary active functional goals. Significantly more patients achieved their secondary passive goal with onaBoNT-A plus standard of care vs placebo plus standard of care at week 24 , but not at week 12 or week $52 .{ }^{39}$

IncoBoNT-A. Two new Class I trials ${ }^{40, e 1}$ showed significant improvement in tone reduction with incoBoNT-A. In the first trial, incoBoNT-A produced a greater proportion of participants with $\geq 1$-point improvement in the Ashworth scale score at 4 weeks (odds ratio 3.97, 95\% CI 1.9-8.3). In the second study, participants treated with incoBoNT-A demonstrated larger reductions in Ashworth scale scores of muscle groups in the primary target clinical pattern $(-0.9$ with incoBoNT-A vs -0.5 with placebo, $p<0.001)$ as well as a greater proportion with $>1$-point improvement $(69.6 \%$ vs $37.5 \%$, respectively). Both studies also showed that incoBoNT-A produced greater response in all domains of the DAS and global assessment of benefit. The open-label extension study of the first trial showed persistence of benefit without detection of neutralizing antibodies. ${ }^{\mathrm{e} 2}$

RimaBoNT-B. In a newer Class I study, ${ }^{\mathrm{e} 3}$ patients were randomized to 1 of 2 doses of rimaBoNT-B or placebo. Patients randomized to either BoNT dose had improved active elbow extension vs placebo $\left(+8.3^{\circ}, 95 \%\right.$ CI $\left.1.1^{\circ}-15.5^{\circ}\right)$. There was no significant change as compared with placebo in upper limb function as measured by the Modified Frenchay Scale.

Conclusions. AboBoNT-A, incoBoNT-A, and onaBoNT-A are established as safe and effective for the reduction of adult upper limb spasticity and improvement of passive function (multiple Class I studies for all preparations).

RimaBoNT-B is probably safe and effective for the reduction of adult upper limb spasticity (1 Class I study).

Data are inadequate to determine the efficacy of aboBoNT-A, onaBoNT-A, incoBoNT-A, or rimaBoNT-B for improvement of active function associated with adult upper limb spasticity (Class I studies, inconsistent results dependent on active functional outcome).

Recommendations. For focal manifestations of adult spasticity involving the upper limb, aboBoNT-A, incoBoNT-A, and onaBoNT-A should be offered (Level A), and rimaBoNT-B should be considered (Level B), as treatment options.
Lower extremity spasticity. One placebo-controlled Class I study ${ }^{e 4}$ published since the 2008 guideline examined aboBoNT-A use in multiple sclerosis and observed reduced pain in both legs in patients randomized to aboBoNT-A (RD proportion of patients reporting decreased pain at 12 weeks $29.9 \%, 95 \% \mathrm{CI}$ $10.9 \%-46 \%)$. Three Class I studies of onaBoNT-A in the treatment of adult lower limb spasticity ${ }^{\mathrm{e}-\mathrm{e} 7}$ demonstrated significant reduction in tone but found inconsistent results in regard to functional measures.

The literature search did not identify studies meeting inclusion criteria addressing the efficacy of incoBoNT-A or rimaBoNT-B for adult lower limb spasticity.

Conclusions. AboBoNT-A and onaBoNT-A are established as safe and effective for the reduction of adult lower limb spasticity (multiple Class I studies).

Data are inadequate to determine the efficacy of incoBoNT-A or rimaBoNT-B for improvement of active function in adult lower limb spasticity.

Data are inadequate to determine the efficacy of aboBoNT-A, onaBoNT-A, incoBoNT-A, or rimaBoNT-B for improvement of active function associated with adult lower-limb spasticity (no studies available or inconsistent results dependent on specific outcome from multiple Class I studies).

Recommendations. For focal manifestations of adult spasticity involving the lower limb that warrant treatment, onaBoNT-A and aboBoNT-A should be offered (Level A) as treatment options.

There is insufficient evidence to support or refute a benefit of incoBoNT-A or rimaBoNT-B for treatment of adult lower limb spasticity.

Comparative studies. In a Class I study of patients with adult upper limb spasticity, onaBoNT-A was superior to tizanidine (TZD) for improving wrist and finger flexor tone, whereas TZD showed no benefit over placebo. Notably, the high incidence of AEs with TZD limited dose titration (90.5\% of patients receiving TZD experienced one or more AEs). ${ }^{35}$

Conclusions. OnaBoNT-A is probably superior to TZD for reducing upper extremity tone (1 Class I study) in adult spasticity.

Recommendations. OnaBoNT-A should be considered as a treatment option before TZD for treating adult upper extremity spasticity (Level B).

Techniques to optimize response to BoNT. Two Class I studies $^{\mathrm{e} 8, \mathrm{e} 9}$ demonstrated that high-volume injections of onaBoNT-A and endplate targeting into proximal upper extremity muscles are probably effective strategies for enhancing tone reduction in adult spasticity. One Class II study ${ }^{\text {e10 }}$ compared 3 different techniques for guiding BoNT injection placement (manual needle placement, electrical stimulation, and ultrasonography) and did not find consistent outcomes favoring one technique. 
Conclusions. Both high-volume, low-potency injections of onaBoNT-A and endplate targeting into proximal upper extremity muscles are probably effective strategies for enhancing tone reduction in adult spasticity (1 Class I study for each technique).

There is insufficient evidence to support or refute the superiority of specific techniques for guiding BoNT injection placement (inconsistent outcomes from 1 Class II study).

Recommendations. Both high-volume, low-potency injections of onaBoNT-A and endplate targeting of onaBoNT-A into proximal upper extremity muscles should be considered to enhance tone reduction in spasticity (Level B).

Clinical context. Although BoNT can reduce increased tone in spasticity, the impact of BoNT injections on functional outcomes is mixed, suggesting that potential functional gains are highly patient-specific. Because of the lack of comparative trials, there is insufficient evidence to indicate that any one of the BoNT formulations is superior to the others.

Headache. Chronic migraine. Chronic migraine (CM) refers to migraine attacks occurring 15 days or more monthly for at least 3 months, with attacks lasting 4 hours or more. ${ }^{\text {e1l }}$ Episodic migraine (EM) refers to migraine with a lesser frequency of attack. The 2008 guideline found inconsistent results from 4 Class II studies comparing onaBoNT-A with placebo, resulting in insufficient evidence to support or refute a benefit of BoNT for treatment of CM. ${ }^{3}$

Comparison of BoNT with placebo. Two Class I placebocontrolled studies ${ }^{\mathrm{e} 2, \mathrm{e} 13}$ published since the 2008 guideline met inclusion criteria. In one study, ${ }^{\mathrm{e} 12}$ onaBoNT-A was ineffective for changes from baseline for total headache episodes but was effective for the secondary endpoint of change in frequency of total headache days/28 days (mean intergroup difference -1.4 days, $95 \% \mathrm{CI}-2.4$ to -0.40 ). In the second study, ${ }^{\text {e13 }}$ onaBoNT-A was effective for reducing total headache days/28 days from baseline to weeks 21-24 posttreatment. Nine fewer headache days were seen in the BoNT-A group, with 6.7 in the placebo group $(p<$ 0.001). In both studies the placebo response was high.

Several follow-up reports describing pooled analyses of both Class I studies have been published. One Class I follow-up report ${ }^{\mathrm{e} 14}$ described significant reduction in headache impact and improvement in health-related QOL after 24 weeks of double-blind treatment (proportion of patients with severe Headache Impact Test scores $67.6 \%$ of patients given BoNT vs $78.2 \%$ of patients given placebo, $p<0.001$ ).

Comparison of BoNT with other headache preventive treatments. One Class III study ${ }^{\mathrm{e} 15}$ demonstrated similar efficacy for onaBoNT-A and topiramate in CM. No other studies comparing oral preventive medications with BoNT injections met inclusion criteria. There also are no studies comparing different BoNT serotypes in headache.

AEs of onaBoNT-A included neck pain and muscle weakness.

Conclusions. OnaBoNT-A is established as safe and effective for reducing the number of headache days in CM (2 Class I studies) and probably effective for improving health-related QOL (1 Class I study).

There is insufficient evidence to compare the effectiveness of BoNT with that of oral prophylactic topiramate. No Class I or II studies of other formulations of BoNT in CM have been published.

Recommendations. OnaBoNT-A should be offered as a treatment option to patients with CM to increase the number of headache-free days (Level A) and should be considered to reduce headache impact on health-related QOL (Level B).

Clinical context. Although the reduction of headache days with onaBoNT-A was statistically superior to placebo in 2 Class I studies, the magnitude of the difference is small (1.7 and 2.3).

Episodic migraine. The 2008 guideline conclusion, ${ }^{3}$ based on 2 Class I and 2 Class II studies, indicates onaBoNT-A injection is probably ineffective for treatment of EM. One Class I study ${ }^{\mathrm{e} 16}$ published since the 2008 guideline compared onaBoNT-A at doses of 75 $\mathrm{U}, 150 \mathrm{U}$, and $225 \mathrm{U}$ with placebo, using 3 treatment cycles 3 months apart. OnaBoNT-A was ineffective for reducing migraine frequency from baseline to day 180 .

Conclusion. OnaBoNT-A is ineffective for the treatment of EM (3 Class I studies, 2 from the 2008 report).

Recommendation. OnaBoNT-A should not be offered as a treatment for EM (Level A).

Tension-type headache. No new studies were identified that would have changed the conclusion of the 2008 guideline. ${ }^{3}$ BoNT injection is probably ineffective for treating chronic tension-type headaches (2 Class I studies).

\section{AUTHOR CONTRIBUTIONS}

David M. Simpson: study concept and design, acquisition of data, analysis or interpretation of data, drafting/revising the manuscript, critical revision of the manuscript for important intellectual content, study supervision. Mark Hallett: study concept and design, acquisition of data, analysis or interpretation of data, drafting/revising the manuscript, critical revision of the manuscript for important intellectual content, study supervision. Eric J. Ashman: acquisition of data, analysis or interpretation of data, drafting/revising the manuscript, critical revision of the manuscript for important intellectual content. Cynthia L. Comella: acquisition of data, analysis or interpretation of data, drafting/revising the manuscript, critical revision of the manuscript for important intellectual content. Mark W. Green: acquisition of data, analysis or interpretation of data, drafting/revising the manuscript, critical revision of the manuscript for important intellectual content. Gary S. Gronseth: study concept and design, acquisition of data, analysis or interpretation of data, drafting/ revising the manuscript, critical revision of the manuscript for important intellectual content. Melissa J. Armstrong: acquisition of data, analysis or 
interpretation of data, drafting/revising the manuscript, critical revision of the manuscript for important intellectual content. David Gloss: acquisition of data, analysis or interpretation of data, drafting/revising the manuscript, critical revision of the manuscript for important intellectual content. Sonja Potrebic: acquisition of data, analysis or interpretation of data, drafting/revising the manuscript, critical revision of the manuscript for important intellectual content. Joseph Jankovic: acquisition of data, analysis or interpretation of data, drafting/revising the manuscript, critical revision of the manuscript for important intellectual content. Barbara P. Karp: acquisition of data, analysis or interpretation of data, drafting/revising the manuscript, critical revision of the manuscript for important intellectual content. Markus Naumann: acquisition of data, analysis or interpretation of data, drafting/revising the manuscript, critical revision of the manuscript for important intellectual content. Yuen T. So: acquisition of data, analysis or interpretation of data, drafting/revising the manuscript, critical revision of the manuscript for important intellectual content. Stuart A. Yablon: acquisition of data, analysis or interpretation of data, drafting/revising the manuscript, critical revision of the manuscript for important intellectual content.

\section{ACKNOWLEDGMENT}

The authors thank Erin Hagen, Julie Cox, and Thomas Getchius for editorial assistance.

\section{STUDY FUNDING}

This guideline was developed with financial support from the American Academy of Neurology. Authors who serve as AAN subcommittee members or methodologists (E.J.A., G.S.G., M.J.A., D.G., S.P.) were reimbursed by the AAN for expenses related to travel to subcommittee meetings where drafts of manuscripts were reviewed.

\section{DISCLOSURE}

D. Simpson has received research grants from and served as a consultant for Allergan Inc., Ipsen Ltd., Merz Pharmaceuticals, and Acorda Therapeutics. M. Hallett serves as a chair of the Neurotoxin Institute Advisory Council and has received research grants from Allergan Inc. and Merz Pharmaceuticals. E. Ashman served as a paid editor for Neurology ${ }^{\circledR}$ from 2011 to 2013. C. Comella has received research grants from and has served as a consultant for Allergan Inc., Ipsen Ltd., Merz Pharmaceuticals, and Revance Pharmaceuticals. M. Green and G. Gronseth report no disclosures relevant to the manuscript. M. Armstrong serves on the Level of Evidence Review Team for Neurology (not compensated financially) and serves as an evidence-based methodologist for the AAN. She has no conflicts of interest related to the topic of this guideline. D. Gloss and S. Potrebic report no disclosures relevant to the manuscript. J. Jankovic has received research grants from and served as a consultant for Allergan Inc., Ipsen Ltd., and Merz Pharmaceuticals. B. Karp has received a research grant from Allergan Inc. M. Naumann has served as a consultant for Allergan Inc. and Ipsen Ltd. Y. So reports no disclosures relevant to the manuscript. S. Yablon has served as a consultant for Allergan Inc., Ipsen Ltd., Medtronic Inc., and Merz Pharmaceuticals. Go to Neurology.org for full disclosures.

\section{DISCLAIMER}

Clinical practice guidelines, practice advisories, systematic reviews, and other guidance published by the American Academy of Neurology and its affiliates are assessments of current scientific and clinical information provided as an educational service. The information: (1) should not be considered inclusive of all proper treatments, methods of care, or as a statement of the standard of care; (2) is not continually updated and may not reflect the most recent evidence (new evidence may emerge between the time information is developed and when it is published or read); (3) addresses only the question(s) specifically identified; (4) does not mandate any particular course of medical care; and (5) is not intended to substitute for the independent professional judgment of the treating provider, as the information does not account for individual variation among patients. In all cases, the selected course of action should be considered by the treating provider in the context of treating the individual patient. Use of the information is voluntary. AAN provides this information on an as-is basis, and makes no warranty, expressed or implied, regarding the information. AAN specifically disclaims any warranties of merchantability or fitness for a particular use or purpose. AAN assumes no responsibility for any injury or damage to persons or property arising out of or related to any use of this information or for any errors or omissions.

\section{CONFLICT OF INTEREST}

The American Academy of Neurology is committed to producing independent, critical, and truthful clinical practice guidelines (CPGs). Significant efforts are made to minimize the potential for conflicts of interest to influence the recommendations of this CPG. To the extent possible, the AAN keeps separate those who have a financial stake in the success or failure of the products appraised in the CPGs and the developers of the guidelines. Conflict of interest forms were obtained from all authors and reviewed by an oversight committee prior to project initiation. AAN limits the participation of authors with substantial conflicts of interest. The AAN forbids commercial participation in, or funding of, guideline projects. Drafts of the guideline have been reviewed by at least 3 AAN committees, a network of neurologists, Neurology peer reviewers, and representatives from related fields. The AAN Guideline Author Conflict of Interest Policy can be viewed at www.aan.com. For complete information on this process, access the 2004 AAN process manual. ${ }^{4}$

Received June 8, 2015. Accepted in final form December 21, 2015.

\section{REFERENCES}

1. Simpson M, Gracies JM, Graham HK, et al; for the Therapeutics and Technology Assessment Subcommittee of the American Academy of Neurology. Assessment: botulinum neurotoxin for the treatment of spasticity (an evidencebased review): report of the Therapeutics and Technology Assessment Subcommittee of the American Academy of Neurology. Neurology 2008;70:1691-1698.

2. Simpson M, Blitzer A, Brashear A, et al; for the Therapeutics and Technology Assessment Subcommittee of the American Academy of Neurology. Assessment: botulinum neurotoxin for the treatment of movement disorders (an evidence-based review): report of the Therapeutics and Technology Assessment Subcommittee of the American Academy of Neurology. Neurology 2008;70:1699-1706.

3. Naumann M, So Y, Argoff CE, et al; for the Therapeutics and Technology Assessment Subcommittee of the American Academy of Neurology. Assessment: botulinum toxin in the treatment of autonomic disorders and pain (an evidence-based review): report of the Therapeutics and Technology Assessment Subcommittee of the American Academy of Neurology. Neurology 2008;70:1707-1714.

4. American Academy of Neurology. Clinical Practice Guidelines Process Manual, 2004 ed. St. Paul, MN: The American Academy of Neurology; 2004. Available at: https:// www.aan.com/Guidelines/Home/UnderDevelopment. Accessed August 1, 2011.

5. Jankovic J, Comella C, Hanschmann A, Grafe S. Efficacy and safety of incobotulinumtoxinA (NT 201, Xeomin) in the treatment of blepharospasm: a randomized trial. Mov Disord 2011;26:1521-1528.

6. Jankovic J, Orman J. Botulinum A toxin for cranialcervical dystonia: a double-blind, placebo-controlled study. Neurology 1987;37:616-623.

7. Truong D, Comella C, Fernandez HH, Ondo WG; Dysport Essential Blepharospasm Study Group. Efficacy and safety of purified botulinum toxin type A (Dysport) for the treatment of benign essential blepharospasm: a randomized, placebo-controlled, phase II trial. Parkinsonism Relat Disord 2008;14:407-414.

8. Lindeboom R, De Haan R, Aramideh M, Speelman JD. The blepharospasm disability scale: an instrument for the 
assessment of functional health in blepharospasm. Mov Disord 1995;10:444-449.

9. Wabbels B, Reichel G, Fulford-Smith A, Wright N, Roggenkamper P. Double-blind, randomised, parallel group pilot study comparing two botulinum toxin type A products for the treatment of blepharospasm. J Neural Transm 2011;118:233-239.

10. Saad J, Gourdeau A. A direct comparison of onabotulinumtoxinA (Botox) and incobotulinumtoxinA (Xeomin) in the treatment of benign essential blepharospasm: a splitface technique. J Neuroophthalmol 2014;34:233-236.

11. Bentivoglio AR, Fasano A, Ialongo T, Soleti F, Lo Fermo S, Albanese A. Fifteen-year experience in treating blepharospasm with Botox or Dysport: same toxin, two drugs. Neurotox Res 2009;15:224-231.

12. Cillino S, Raimondi G, Guepratte N, et al. Long-term efficacy of botulinum toxin A for treatment of blepharospasm, hemifacial spasm, and spastic entropion: a multicentre study using two drug-dose escalation indexes. Eye 2010;24:600-607.

13. Truong D, Gollomp S, Jankovic J, et al; Xeomin US Blepharospasm Study Group. Sustained efficacy and safety of repeated incobotulinumtoxinA (Xeomin) injections in blepharospasm. J Neural Transm 2013;120:1345-1353.

14. Kollewe K, Mohammadi B, Köhler S, et al. Blepharospasm: long-term treatment with either Botox, Xeomin or Dysport. J Neural Transm 2015;122:427-431.

15. Hallett M, Albanese A, Dressler D, et al. Evidence-based review and assessment of botulinum neurotoxin for the treatment of movement disorders. Toxicon 2013;67: 94-114.

16. Defazio G, Jankovic J, Giel JL, Papapetropoulos S. Descriptive epidemiology of cervical dystonia. Tremor Other Hyperkinet Mov 2013;3.

17. Comella CL, Jankovic J, Truong DD, Hanschmann A, Grafe S; U.S. XEOMIN Cervical Dystonia Study Group. Efficacy and safety of incobotulinumtoxinA (NT 201, XEOMIN, botulinum neurotoxin type A, without accessory proteins) in patients with cervical dystonia. J Neurol Sci 2011;308:103-109.

18. Boyce MJ, Canning CG, Mahant N, Morris J, Latimer J, Fung VS. The Toronto Western Spasmodic Torticollis Rating Scale: reliability in neurologists and physiotherapists. Parkinsonism Relat Disord 2012;18:635-637.

19. Evidente VG, Fernandez HH, LeDoux MS, et al. A randomized, double-blind study of repeated incobotulinumtoxinA (Xeomin) in cervical dystonia. J Neural Transm 2013;120:1699-1707.

20. Charles D, Brashear A, Hauser RA, Li HI, Boo LM, Brin MF. Efficacy, tolerability, and immunogenicity of onabotulinumtoxinA in a randomized, double-blind, placebo-controlled trial for cervical dystonia. Clin Neuropharmacol 2012;35:208-214.

21. Comella CL, Jankovic J, Shannon KM, et al. Comparison of botulinum toxin serotypes A and B for the treatment of cervical dystonia. Neurology 2005;65:1423-1429.

22. Pappert EJ, Germanson T; Myobloc/Neurobloc European Dystonia Study Group. Botulinum toxin type B vs. type A in toxin-naïve patients with cervical dystonia: randomized, double-blind, noninferiority trial. Mov Disord 2008;23: 510-517.

23. Odergren T, Hjaltason H, Kaakkola S, et al. A double blind, randomised, parallel group study to investigate the dose equivalence of Dysport and Botox in the treatment of cervical dystonia. J Neurol Neurosurg Psychiatry 1998;64: 6-12.

24. Yun JY, Kim JW, Kim HT, et al. Dysport and Botox at a ratio of 2.5:1 units in cervical dystonia: a double-blind, randomized study. Mov Disord 2015;30:206-213.

25. Rystedt A, Zetterberg L, Burman J, Nyholm D, Johansson A. A comparison of Botox $100 \mathrm{U} / \mathrm{mL}$ and Dysport $100 \mathrm{U} / \mathrm{mL}$ using dose conversion ratio $1: 3$ and $1: 1.7$ in the treatment of cervical dystonia: a double-blind, randomized, crossover trial. Clin Neuropharmacol 2015;38: 170-176.

26. Truong D, Brodsky M, Lew M, et al. Long-term efficacy and safety of botulinum toxin type A (Dysport) in cervical dystonia. Parkinsonism Relat Disord 2010;16:316-323.

27. Brin MF, Comella CL, Jankovic J, Lai F, Naumann M; CD-017 BoNTA Study Group. Long-term treatment with botulinum toxin type $\mathrm{A}$ in cervical dystonia has low immunogenicity by mouse protection assay. Mov Disord 2008;23:1353-1360.

28. Jankovic J, Adler CH, Charles D, et al. Primary results from the cervical dystonia patient registry for observation of onabotulinumtoxinA efficacy (CD PROBE). J Neurol Sci 2015;349:84-93.

29. Delgado MR, Hirtz D, Aisen M, et al; for the Quality Standards Subcommittee of the American Academy of Neurology and the Practice Committee of the Child Neurology Society. Practice parameter: pharmacologic treatment of spasticity in children and adolescents with cerebral palsy (an evidence-based review): report of the Quality Standards Subcommittee of the American Academy of Neurology and the Practice Committee of the Child Neurology Society. Neurology 2010;74:336-343.

30. McCrory P, Turner-Stokes L, Baguley IJ, et al. Botulinum toxin A for treatment of upper limb spasticity following stroke: a multi-centre randomized placebo-controlled study of the effects on quality of life and other personcentred outcomes. J Rehabil Med 2009;41:536-544.

31. Shaw LC, Price CI, van Wijck FM, et al; BoTULS Investigators. Botulinum toxin for the upper limb after stroke (BoTULS) trial: effect on impairment, activity limitation, and pain. Stroke 2011;42:1371-1379.

32. Rosales RL, Kong KH, Goh KJ, et al. Botulinum toxin injection for hypertonicity of the upper extremity within 12 weeks after stroke: a randomized controlled trial. Neurorehabil Neural Repair 2012;26:812-821.

33. Gracies JM, Brashear A, Jech R, et al; for the International AbobotulinumtoxinA Adult Upper Limb Spasticity Study Group. Safety and efficacy of abobotulinumtoxinA for hemiparesis in adults with upper limb spasticity after stroke or traumatic brain injury: a double-blind randomised controlled trial. Lancet Neurol 2015;14:992-1001.

34. Lam K, Lau KK, So KK, et al. Can botulinum toxin decrease carer burden in long term care residents with upper limb spasticity? A randomized controlled study. J Am Med Dir Assoc 2012;13:477-484.

35. Simpson DM, Gracies JM, Yablon SA, Barbano R, Brashear A; BoNT/TZD Study Team. Botulinum neurotoxin versus tizanidine in upper limb spasticity: a placebocontrolled study. J Neurol Neurosurg Psychiatry 2009;80: 380-385.

36. Kaji R, Osako Y, Suyama K, Maeda T, Uechi Y, Iwasaki M; GSK1358820 Spasticity Study Group. Botulinum toxin type A in post-stroke upper limb spasticity. Curr Med Res Opin 2010;26:1983-1992. 
37. Marciniak CM, Harvey RL, Gagnon CM, et al. Does botulinum toxin type A decrease pain and lessen disability in hemiplegic survivors of stroke with shoulder pain and spasticity? A randomized, double-blind, placebo-controlled trial. Am J Phys Med Rehabil 2012;91:1007-1019.

38. Jahangir AW, Tan HJ, Norlinah MI, et al. Intramuscular injection of botulinum toxin for the treatment of wrist and finger spasticity after stroke. Med J Malaysia 2007;62:319-322.
39. Ward AB, Wissel J, Borg J, et al; BEST Study Group. Functional goal achievement in post-stroke spasticity patients: the BOTOX Economic Spasticity Trial (BEST). J Rehabil Med 2014;46:504-513.

40. Kaňovský P, Slawek J, Denes Z, et al. Efficacy and safety of botulinum neurotoxin NT 201 in poststroke upper limb spasticity. Clin Neuropharmacol 2009;32: 259-265. 


\section{Neurology}

Practice guideline update summary: Botulinum neurotoxin for the treatment of blepharospasm, cervical dystonia, adult spasticity, and headache: Report of the Guideline Development Subcommittee of the American Academy of Neurology

David M. Simpson, Mark Hallett, Eric J. Ashman, et al.

Neurology 2016;86;1818-1826 Published Online before print April 18, 2016

DOI 10.1212/WNL.0000000000002560

This information is current as of April 18, 2016

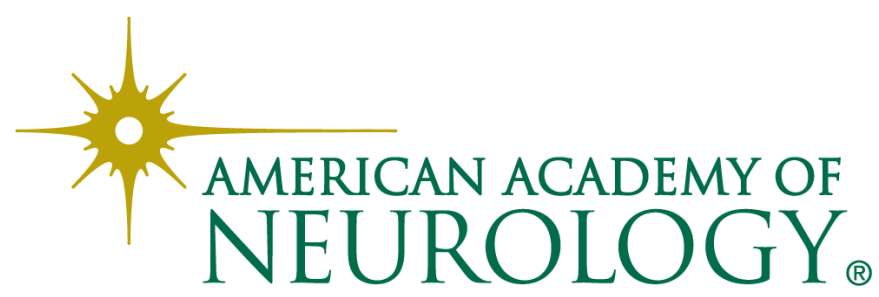




\section{Updated Information \& Services}

\section{Supplementary Material}

References

Citations

Subspecialty Collections

\section{Permissions \& Licensing}

Reprints including high resolution figures, can be found at: http://n.neurology.org/content/86/19/1818.full

Supplementary material can be found at: http://n.neurology.org/content/suppl/2016/04/18/WNL.0000000000002 560.DC1

This article cites 38 articles, 9 of which you can access for free at: http://n.neurology.org/content/86/19/1818.full\#ref-list-1

This article has been cited by 6 HighWire-hosted articles: http://n.neurology.org/content/86/19/1818.full\#\#otherarticles

This article, along with others on similar topics, appears in the following collection(s):

All Headache

http://n.neurology.org/cgi/collection/all_headache

Blepharospasm

http://n.neurology.org/cgi/collection/blepharospasm

Botulinum toxin

http://n.neurology.org/cgi/collection/botulinum_toxin

Dystonia

http://n.neurology.org/cgi/collection/dystonia

Information about reproducing this article in parts (figures,tables) or in its entirety can be found online at:

http://www.neurology.org/about/about_the_journal\#permissions

Information about ordering reprints can be found online:

http://n.neurology.org/subscribers/advertise

Neurology ${ }^{\circledR}$ is the official journal of the American Academy of Neurology. Published continuously since 1951, it is now a weekly with 48 issues per year. Copyright () 2016 American Academy of Neurology. All rights reserved. Print ISSN: 0028-3878. Online ISSN: 1526-632X.

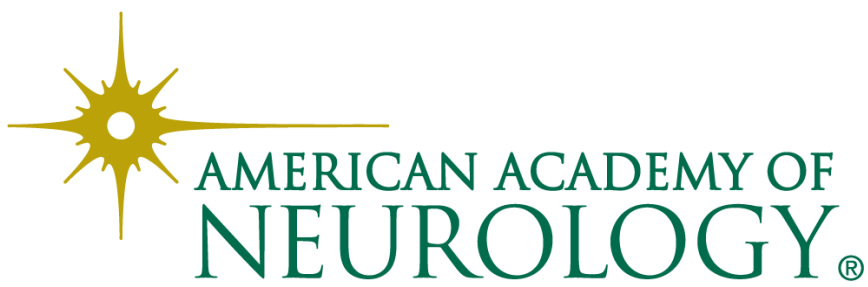

